\title{
Relationship between women's occupational work and bone health: a study from India
}

\author{
Veena Shatrugna*, Bharati Kulkarni, P. Ajay Kumar, N. Balakrishna, K. Usha Rani, \\ G. Chennakrishna Reddy and G. V. Narasimha Rao \\ National Institute of Nutrition (Indian Council of Medical Research), Jamai Osmania P. O., Hyderabad 500 007, India \\ (Received 6 November 2006 - Revised 4 October 2007 - Accepted 22 October 2007 - First published online 21 December 2007)
}

Physical activity is known to influence the bone mass of an individual. Few studies have examined the effect of occupational activities on bone health. The present study investigated the relationship between occupational activities and the bone parameters measured by dual-energy X-ray absorptiometry in 158 women from a low-income group in India. Women involved in three occupations with different bone-loading patterns (beedi (cigarette) makers, sweepers and construction workers) were included in the study. Anthropometric parameters, parity and percentage of menopausal women did not differ significantly between the three groups and dietary intake of Ca was low in all the groups. Bone mineral density (BMD) values of the overall group at all the sites were much lower than those reported from developed countries, possibly due to different body sizes in these regions. Femoral neck and hip BMD were not different in the three groups in spite of marked differences in activity patterns. However, bone area in the femoral neck was higher in the beedi makers compared with sweepers probably due to the squatting position adopted by beedi makers. Lumbar spine BMD was significantly lower among the sweepers when compared with the beedi makers and the groups performing walking and weight-bearing activities (sweepers and construction workers) had a higher prevalence of osteoporosis in the lumbar spine. However, weight-bearing effects of the upper body due to a squatting position were associated with better lumbar spine BMD in the beedi makers. The present study thus indicates that undernutrition might affect the relationship between occupational activities and bone parameters.

Bone mineral density: Physical activity: Occupational activity: Nutrition

A number of studies from India have revealed that men and women belonging to low socio-economic groups sustain osteoporotic hip fractures at a much earlier age than those reported from high-income groups in India and from the Western regions ${ }^{(1-3)}$.

A recent study using the advanced technique of dual-energy X-ray absorptiometry for the measurement of bone mineral density (BMD) indicated a high prevalence of poor bone health in Indian women from a low-income group. This study also highlighted the fact that undernutrition as indicated by low body weights and low BMI coupled with inadequate $\mathrm{Ca}$ intakes may be the major determinant of poor bone health in these women. Onset of menopause appears to hasten osteoporotic changes in this population ${ }^{(4)}$.

Apart from the role of genetics, diet and physical activity are known to influence the bone health of an individual. A large number of the population (men, women and children) from low income-groups subsist on diets that have inadequate energy, proteins, $\mathrm{Ca}$ and other micronutrients ${ }^{(5)}$. About $40 \%$ of them suffer from chronic energy deficiency. Even adolescent children from the middle-income group subsist on diets deficient in protective foods ${ }^{(6)}$.
Many epidemiological and experimentally induced exercise studies in human subjects have indicated that physical activity may be crucial in improving and maintaining the bone mass and muscle strength ${ }^{(7-10)}$. Weight-bearing activities are known to produce a maximal osteogenic response in a sitespecific manner ${ }^{(11)}$. But the majority of these studies have examined the relationship between sports-related activities and bone mass in the presence of adequate nutrient intakes. Very few studies have examined the role of occupational activities in the maintenance of bone mass ${ }^{(12)}$. A large number of women from the low-income group are engaged in occupations that necessitate them to hold certain postures for a long time, thereby causing repetitive stress on the musculo-skeletal system. Studies on work-related musculo-skeletal disorders have not looked at the effect of these disorders on the bone health of women. It was hypothesised that the stress of heavy occupational work on women's bodies that are undernourished may in fact be detrimental to bone health.

The present study examined the relationship between occupational work and bone health in women from the low socioeconomic group from Hyderabad, India. 


\section{Subjects and methods}

\section{Sample size}

Assuming a $95 \% \mathrm{CI}$ and standard deviation of lumbar spine BMD of $0.14 \mathrm{~g} / \mathrm{cm}^{2}$ and an expected difference of $0.04 \mathrm{~g} / \mathrm{cm}^{2}$ (based on earlier studies in the same population ${ }^{(4)}$ ), the required sample size was forty-eight. It was therefore decided to recruit about fifty-five women in each occupational group.

Adult women from a large urban slum, Addagutta (Hyderabad, India), aged 30-60 years were enumerated and their occupations were recorded. A list of over twenty occupations was thus made. It was decided to recruit women from three occupations (sweepers, construction workers and beedi makers) because of the specific nature of bone-loading work involved in these occupations. A stratified random sample of fifty-five women per occupational group (from the three groups) were randomly selected. It was ensured that the recruited subjects were involved in their occupation for a minimum of 5 years. Some of the details of the occupations have been reported elsewhere ${ }^{(13)}$. All the study participants gave informed consent before participating in the study. The research protocol was approved by the Institutional Ethics Committee of National Institute of Nutrition (Hyderabad, India).

Construction workers are involved in weight-bearing activities. They perform various tasks such as walking and carrying head loads of sand and cement during the major part of their $8 \mathrm{~h}$ working day.

Beedi makers squat on the floor often for $2-3 \mathrm{~h}$ continuously or even longer, hunched over their work making up to 500-1000 beedies (a local cigarette, produced by women as part of home-based work) per $d$. Their work is not load bearing.

Sweepers sweep the city roads, walking and brooming in a partially flexed posture. They perform this task for about $6-8 \mathrm{~h}$ per working $\mathrm{d}$.

Background information regarding parity, duration of breast-feeding, menopausal status, age at menopause, etc of all the women was recorded. Anthropometric measurements such as weight and height were carried out using standard procedures. Weight was measured without footwear to the nearest $0.1 \mathrm{~kg}$ on a lever-type SECA balance (Hamburg, Germany). Heights were measured to the nearest $0.1 \mathrm{~cm}$ with a stadiometer (Seca Ltd, Birmingham, UK).

Areal BMD measurements were carried out using dual-energy X-ray absorptiometry (Hologic QDR $4500 \mathrm{~W}$; Waltham, MA, USA) at two sites namely the anteroposterior lumbar spine (L1-L4) and hip as well as the whole body including body composition. All scans and analyses were carried out according to the manufacturer's instructions by a trained technician. The scanner was calibrated daily and its performance was monitored as per the quality assurance protocol. No sign of scanner drift was observed during the study period.

The in vivo precision $(\mathrm{CV})$ was $1 \%$ for lumbar spine and hip BMD and $<1 \%$ for whole-body bone mineral content (BMC) measurements. Manufacturer's normative data were used as a reference range.

A fasting blood sample was drawn in the morning between 09.00 and 10.00 hours in all the subjects and the estimations of biochemical parameters were carried out using standard procedures. $\mathrm{Hb}$ was estimated by the cyanmethaemoglobin method; serum albumin ${ }^{(14)}$, serum tartrate-resistant acid phosphatase $^{(15)}$ and serum bone-specific alkaline phosphatase ${ }^{(16)}$ estimations were carried out on the same day.

The serum was processed, preserved and estimation of serum $\mathrm{Ca}$ was done within a week of sample collection using atomic absorption spectroscopy. Serum parathyroid hormone and vitamin D could not be estimated. The subjects' dietary $\mathrm{Ca}$ intakes were estimated by a standardised FFQ, as described elsewhere ${ }^{(4)}$.

\section{Statistical analysis}

Data were analysed using SPSS 14.0 windows version (SPSS Inc., Chicago, IL, USA). Results are expressed as means and $95 \%$ CI or standard errors of the mean. The mean values of anthropometric and bone parameters were compared by occupation groups using one-way ANOVA with post hoc tests of least significant difference. Prevalences were calculated for biochemical parameters, and to study the association with occupational groups the $\chi^{2}$ test was used. Analysis of covariance (ANCOVA) was also used for comparing the mean values of spine BMD between occupation groups after eliminating the effect of confounding variables such as age, height, weight, $\mathrm{Ca}$ intake, lean mass and fat mass. Two-tailed tests were used for the level of significance. Statistical significance was set at $P<0 \cdot 05$.

\section{Results}

A total of 165 women were recruited for the study. However, complete data were available in 158 subjects. Their distribution in the three occupational groups (beedi makers, sweepers and construction workers) is indicated in Table 1. Some women had metal jewellery that interfered with the measurements. Therefore whole-body measurements were available in forty-eight beedi makers, forty-two sweepers and fifty-one construction workers. The mean age, weight, height and BMI of the subjects were not significantly different in the three occupational groups (Table 1). The mean parity and proportion of post-menopausal women were also not different in the three groups. Diets were mainly cereal based with very low intake of Ca-rich foods including milk and milk products. Mean dietary Ca intake was $304(95 \%$ CI 295, 312) mg/d and was not significantly different between the three occupational groups.

The areal BMD values of the three groups as well as their body composition data are presented in Table 2 . The $\mathrm{T}$-scores at the neck and hip in the pooled sample were in the osteopenic range and the spine was close to osteoporosis. When the bone parameters were analysed in relation to the occupational groups, it was observed that the BMD and $\mathrm{T}$-scores of the lumbar spine were significantly lower in sweepers when compared with the beedi makers $(P=0.036)$. The lumbar spine BMD and T-score of the construction workers were in between. Spine BMD were significantly different between occupational groups using ANCOVA $(P=0.02)$ (power 0.71$)$. There were no differences in the bone parameters at other sites between the occupational groups except that the femoral neck area of sweepers was significantly smaller when compared with the beedi makers $(P=0 \cdot 019)$ (Table 2). 
Table 1. Characteristics of the study group

(Mean values and $95 \%$ confidence intervals)

\begin{tabular}{|c|c|c|c|c|c|c|c|c|c|}
\hline & \multicolumn{2}{|c|}{ Beedi makers } & \multicolumn{2}{|c|}{ Sweepers } & \multicolumn{2}{|c|}{ Construction workers } & \multicolumn{2}{|c|}{ Total } & \multirow[b]{2}{*}{$P$} \\
\hline & Mean & $95 \% \mathrm{Cl}$ & Mean & $95 \% \mathrm{Cl}$ & Mean & $95 \% \mathrm{Cl}$ & Mean & $95 \% \mathrm{Cl}$ & \\
\hline Subjects $(n)$ & \multicolumn{2}{|c|}{53} & \multicolumn{2}{|c|}{52} & \multicolumn{2}{|c|}{53} & \multicolumn{2}{|c|}{158} & - \\
\hline Age (years) & 38.8 & $37 \cdot 1,40 \cdot 6$ & $40 \cdot 9$ & $38 \cdot 8,43 \cdot 1$ & 41.4 & $39 \cdot 0,43 \cdot 8$ & $40 \cdot 4$ & $39 \cdot 2,41 \cdot 6$ & 0.181 \\
\hline Weight (kg) & 48.9 & $46 \cdot 3,51 \cdot 6$ & 48.9 & $45 \cdot 8,52 \cdot 0$ & 45.9 & $43 \cdot 9,48 \cdot 1$ & 48.0 & $46 \cdot 4,49 \cdot 5$ & 0.189 \\
\hline Height (cm) & $149 \cdot 3$ & $147 \cdot 8,150 \cdot 8$ & 148.5 & $147.1,149.9$ & $148 \cdot 1$ & $146 \cdot 9,149 \cdot 3$ & $148 \cdot 6$ & $147 \cdot 8,149 \cdot 4$ & 0.471 \\
\hline BMI $\left(\mathrm{kg} / \mathrm{m}^{2}\right)$ & 21.9 & $20 \cdot 9,22 \cdot 9$ & $22 \cdot 1$ & $20 \cdot 9,23 \cdot 2$ & $21 \cdot 0$ & $20 \cdot 0,21 \cdot 9$ & $21 \cdot 6$ & $21 \cdot 0,22 \cdot 2$ & 0.283 \\
\hline Parity & $2 \cdot 8$ & $2 \cdot 5,3 \cdot 1$ & $3 \cdot 3$ & $2 \cdot 9,3 \cdot 6$ & 3.3 & $2 \cdot 9,3.6$ & $3 \cdot 1$ & $2 \cdot 9,3 \cdot 3$ & 0.071 \\
\hline Post-menopausal women (\%) & \multicolumn{2}{|c|}{36} & \multicolumn{2}{|c|}{49} & \multicolumn{2}{|c|}{40} & \multicolumn{2}{|c|}{41.4} & 0.375 \\
\hline Dietary Ca intake $(\mathrm{mg} / \mathrm{d})$ & 304 & 290,317 & 304 & 287,321 & 303 & 289,317 & 304 & 295, 312 & 0.993 \\
\hline
\end{tabular}

The lean body mass was not significantly different among the occupational groups. However, construction workers had significantly lower fat mass than the beedi makers $(P=0.024)$. The fat mass of the sweepers was in between. Beedi makers had significantly higher fat percentage than construction workers $(P=0.002$; Table 2$)$.

Nearly half of the women had osteoporosis (T-scores $<-2.5)$ at the spine and one-quarter had osteoporosis at the femoral neck in the pooled sample. The prevalence of osteoporosis almost doubled in sweeper and construction workers group when compared with the beedi maker group (Table 3).

\section{Biochemical parameters}

The mean values of the biochemical parameters were not different between the three occupational groups except for serum $\mathrm{Ca}$, which was significantly lower in the sweepers when compared with the others (1.96 (SEM 0.036) $\mathrm{mmol} / \mathrm{l}$ (sweepers) v. $2 \cdot 32$ (SEM 0.018) $\mathrm{mmol} / \mathrm{l}$ in the rest).

\section{Discussion}

This is the first study from India which investigates the relationship between women's occupational work and their bone health, and highlights the problem of poor bone health in the women workers from low-income groups in India.

The overall nutritional status of these women as indicated by their weights, heights and BMI was similar to that reported by National Nutrition Monitoring Bureau surveys, which are large-scale nutrition surveys of the low socio-economic population from India. The mean weights and heights of the women were much lower than the mean weights and heights

Table 2. Bone parameters by occupation

(Mean values and $95 \%$ confidence intervals)

\begin{tabular}{|c|c|c|c|c|c|c|c|c|c|}
\hline & \multicolumn{2}{|c|}{ Beedi makers } & \multicolumn{2}{|c|}{ Sweepers } & \multicolumn{2}{|c|}{ Construction workers } & \multicolumn{2}{|r|}{ Total } & \multirow[b]{2}{*}{$P$} \\
\hline & Mean & $95 \% \mathrm{Cl}$ & Mean & $95 \% \mathrm{Cl}$ & Mean & $95 \% \mathrm{Cl}$ & Mean & $95 \% \mathrm{Cl}$ & \\
\hline \multicolumn{10}{|l|}{ Femoral neck } \\
\hline BMC (g) & 2.951 & $2 \cdot 800,3 \cdot 102$ & $2 \cdot 726$ & $2 \cdot 548,2.905$ & $2 \cdot 857$ & $2.683,3.031$ & $2 \cdot 846$ & $2 \cdot 750,2 \cdot 942$ & 0.168 \\
\hline $\mathrm{BA}\left(\mathrm{cm}^{2}\right)$ & $4 \cdot 206^{a}$ & $4.060,4.352$ & $3.847^{\mathrm{b}}$ & $3.643,4.050$ & $4 \cdot 004^{a, b}$ & $3 \cdot 818,4 \cdot 189$ & $4 \cdot 021$ & $3.917,4.125$ & 0.019 \\
\hline $\operatorname{BMD}\left(\mathrm{g} / \mathrm{cm}^{2}\right)$ & 0.702 & $0.675,0.729$ & 0.710 & $0.679,0.740$ & 0.714 & $0.683,0.746$ & 0.709 & $0.692,0.726$ & 0.845 \\
\hline \multicolumn{10}{|l|}{ Нip } \\
\hline $\mathrm{BMC}(\mathrm{g})$ & $20 \cdot 735$ & $19 \cdot 693,21 \cdot 777$ & $21 \cdot 173$ & $19 \cdot 920,22 \cdot 425$ & $21 \cdot 640$ & $20 \cdot 596,22 \cdot 685$ & $21 \cdot 183$ & $20.551,21 \cdot 814$ & 0.511 \\
\hline $\mathrm{BA}\left(\mathrm{cm}^{2}\right)$ & $27 \cdot 119$ & $26 \cdot 454,27 \cdot 784$ & $27 \cdot 552$ & $26 \cdot 793,28 \cdot 312$ & $27 \cdot 876$ & $27 \cdot 260,28 \cdot 493$ & 27.515 & $27 \cdot 128,27 \cdot 903$ & 0.284 \\
\hline $\operatorname{BMD}\left(\mathrm{g} / \mathrm{cm}^{2}\right)$ & 0.762 & $0.734,0.790$ & 0.765 & $0.730,0.799$ & 0.776 & $0.745,0.806$ & 0.767 & $0.750,0.785$ & 0.803 \\
\hline T-score & -1.77 & $-2 \cdot 01,-1.54$ & $-1 \cdot 75$ & $-2.04,-1.46$ & -1.66 & $-1.91,-1.40$ & $-1 \cdot 73$ & $-1.87,-1.58$ & 0.793 \\
\hline \multicolumn{10}{|l|}{ Lumbar spine } \\
\hline $\mathrm{BMC}(\mathrm{g})$ & 39.533 & $37.401,41.666$ & $35 \cdot 862$ & $33 \cdot 463,38 \cdot 262$ & $37 \cdot 119$ & $34.829,39.409$ & 37.515 & $36 \cdot 209,38 \cdot 822$ & 0.070 \\
\hline $\mathrm{BA}\left(\mathrm{cm}^{2}\right)$ & $47 \cdot 479$ & $46 \cdot 218,48 \cdot 741$ & $46 \cdot 732$ & $45.492,47.971$ & $46 \cdot 584$ & $45 \cdot 561,47 \cdot 607$ & 46.933 & $46 \cdot 264,47 \cdot 601$ & 0.513 \\
\hline \multicolumn{10}{|l|}{ Whole body* } \\
\hline $\mathrm{BMC}(\mathrm{g})$ & 1586 & 1528,1643 & 1541 & 1461,1622 & 1580 & 1506,1654 & 1570 & 1530,1610 & 0.642 \\
\hline $\mathrm{BA}\left(\mathrm{cm}^{2}\right)$ & 1573 & 1538,1609 & 1539 & 1487,1591 & 1560 & 1525,1596 & 1558 & 1535,1581 & 0.505 \\
\hline BMD $\left(\mathrm{g} / \mathrm{cm}^{2}\right)$ & 1.01 & $0.989,1.032$ & 0.996 & $0.972,1.020$ & 1.008 & $0.980,1.036$ & 1.005 & $0.991,1.019$ & 0.706 \\
\hline Lean mass (kg) & 29.9 & $28.67,31.08$ & $30 \cdot 2$ & $28 \cdot 74,31 \cdot 66$ & $29 \cdot 7$ & $28 \cdot 62,30 \cdot 69$ & 29.9 & $29 \cdot 20,30 \cdot 58$ & 0.821 \\
\hline Fat mass $(\mathrm{kg})$ & $17 \cdot 1^{\mathrm{a}}$ & $15 \cdot 47,18 \cdot 76$ & $15 \cdot 2^{a, b}$ & $13 \cdot 33,17 \cdot 16$ & $14 \cdot 1^{b}$ & $12 \cdot 69,15 \cdot 42$ & $15 \cdot 4$ & $14 \cdot 51,16 \cdot 39$ & 0.024 \\
\hline Fat $(\%)$ & $34 \cdot 4^{\mathrm{a}}$ & $32 \cdot 84,36 \cdot 02$ & $31 \cdot 3^{a, b}$ & $29 \cdot 35,33 \cdot 19$ & $30 \cdot 3^{b}$ & $28 \cdot 65,32 \cdot 03$ & $32 \cdot 0$ & $30.99,33.03$ & 0.002 \\
\hline
\end{tabular}

BMC, bone mineral content; BA, bone area; BMD, bone mineral density.

a,b Values within a row with unlike superscript letters were significantly different $(P<0.05)$.

* Subjects: beedi makers, $n$ 48; sweepers, $n$ 42; construction workers, $n 51$. 
Table 3. Prevalence of osteoporosis (T-score $<-2.5$ ) by occupation of women

(Percentages)

\begin{tabular}{lccccc}
\hline & Beedi makers & Sweepers & Construction workers & Total & $P$ \\
\hline Femoral neck & 28.3 & $25 \cdot 5$ & $32 \cdot 1$ & 28.7 & 0.710 \\
Hip & 22.6 & 23.5 & 20.8 & 22.3 & 0.966 \\
Spine & $26.4^{\mathrm{a}}$ & $57.7^{\mathrm{b}}$ & $49 \cdot 1^{\mathrm{b}}$ & 44.3 & 0.016 \\
\hline a,b Values within a & &
\end{tabular}

a,b Values within a row with unlike superscript letters were significantly different $(P<0.05)$.

of high-income group women from India ${ }^{(17)}$ and the Western reports (values for high-income group: weight 57.6 (SEM 1.17) $\mathrm{kg}$; height $156.3(\mathrm{SEM} 0.61) \mathrm{cm}$ ). It was obvious that the study population had both weight and height deficits. As a result, the mean BMI of the present study group was in the normal range in spite of their low weights. As mentioned in the results, the dietary Ca intakes were only about $300 \mathrm{mg} / \mathrm{d}$, which is almost $700 \mathrm{mg}$ less than the RDA in the West.

The bone parameters of the pooled sample were comparable with our earlier report on the low socio-economic group ${ }^{(4)}$ and were significantly lower than the Western data and the values reported for the high-income group from India ${ }^{(17)}$. This can be partially explained by the large body sizes of the well-nourished high-income group from India and Western population.

When the bone parameters were analysed in relation to the occupational work status, it was surprising that the areal BMD and T-scores at the femoral neck and hip and whole-body BMC were not significantly different in the three groups, though there were marked differences in the type and duration of bone-loading activities between the beedi makers and the other two groups. However, the bone area at the femoral neck was significantly higher in the beedi makers without significant changes in the BMC or BMD (Table 2). Earlier studies from this Institute highlight the importance of a nonsignificant increase in bone area but with decreased BMC resulting in a significant decrease of BMD with increasing age and menopause in this group of women ${ }^{(4)}$. However, increased weights resulted in significant increase in BMD as a result of increased bone area and BMC at the femoral neck. This finding of higher bone areas without loss of BMC in beedi makers needs further investigation. Measurements of markers of bone turnover (of formation and resorption) might throw light on the type of bone modelling in beedi makers due to their squatting postures. It may be speculated that increase in bone area without decrease in BMC might reinforce a potentially weak structure and protect beedi makers from early fractures.

Beedi makers perform their tasks in the sitting position. Sweepers' activities involve walking in a partially flexed posture without load bearing. However, construction workers walk and carry heavy loads. Therefore, it was perplexing that walking among sweepers and walking and load-bearing activities of construction workers were not associated with better BMD at the weight-bearing regions, i.e. femoral neck and hip. This is in contrast to a number of epidemiological studies that have indicated benefits of load-bearing activities on bone status ${ }^{(18,19)}$. A number of experimental studies have also demonstrated that it is possible to achieve gains in bone mass even in post-menopausal women at sites exposed to osteogenic stimulation of weight-bearing activities ${ }^{(20,21)}$. A case-control study of hip fractures in Canada provides evidence of the protective effect of moderate occupational activities which include bone loading, even though bone densities were not studied ${ }^{(22)}$. It may be speculated that poor dietary intakes especially of $\mathrm{Ca}$ and other nutrients appear to be unfavourable to the osteogenic stimulation of weight-bearing activities in this class of women. The specific roles of low $\mathrm{Ca}$ intakes and continuous work in a fixed posture with multiple nutrient deficiencies need further investigation.

When lumbar spine BMD and T-scores were analysed in the three occupational groups, it was observed that sweepers had significantly lower BMD and T-score when compared with the beedi makers. The construction workers were in between (Table 2). When the prevalence of osteoporosis was assessed in relation to the occupation groups, it was observed that osteoporosis at the lumbar spine almost doubled in the case of sweepers and construction workers when compared with the beedi makers (Table 3). Considering the fact that beedi makers, sweepers and construction workers were age-, weight- and menopausal status-matched, the differences in lumbar spine BMD and T-score may be largely attributed to the occupational activities of sweepers. This has been further confirmed by using ANCOVA. Differences in the BMD at the spine were significant even after controlling for possible confounding factors such as age, height, weight, $\mathrm{Ca}$ intake, lean mass and fat mass. It is, therefore, disturbing to note that the walking and load-bearing activities of sweepers and construction workers were not associated with better BMD of the hip but instead were related to a higher prevalence of osteoporosis at the spine among these two occupation groups. On the contrary, the sitting activity of the beedi makers was associated with a better lumbar spine BMD. A study in male long-distance runners from Denmark has shown reduced lumbar spine bone mass and increased bone turnover when compared with controls ${ }^{(23)}$. The authors speculate that the mechanical strain imposed by excessive physical activity in healthy young adults may have resulted in inflammatory processes, increased cytokine production in bone tissue and increased osteoclastic activity. It is possible that prolonged repetitive work-related strain on the spine of sweepers and construction workers with inadequate nutritional intakes may have initiated similar inflammatory processes and bone thinning of the lumbar spine in the present study. In addition, there was a significant reduction in serum $\mathrm{Ca}$ levels in sweepers, with marked increases in bone-specific acid phosphatase in over $80 \%$ of the women and increased bone-specific alkaline phosphatase levels in $30 \%$ of the women. Unfortunately, there were no data on vitamin D, serum parathyroid hormone and other markers of bone metabolism in these women.

In a review on the effect of physical activity and its interaction with nutrition on bone health, it has been pointed out 
that the beneficial effect of increased physical activity on bone may only be observed at high Ca intakes $(>1000 \mathrm{mg} / \mathrm{d})$ with no effect at mean $\mathrm{Ca}$ intakes of $<1000 \mathrm{mg} / \mathrm{d}$ even in wellnourished populations ${ }^{(11)}$. The role of increased physical activity with multiple nutrient deficiencies was not explored. The women in the present study had to perform long hours of physical work with multiple nutrient deficiencies. Based on the comparative epidemiological studies of prevalence of hip fractures between Asians such as Chinese and Japanese (high physical activity and low Ca intake) and the US population (low physical activity and high $\mathrm{Ca}$ intakes), it has been suggested that high physical activity may permit an adaptation to low $\mathrm{Ca}$ intakes among the Asians ${ }^{(11,24)}$. These conclusions are based on presumably lower rates of hip fractures in the Chinese and Japanese. Though the Indian population may also be defined as having high physical activity and low $\mathrm{Ca}$ intakes, the Indian population is very different from the Chinese and Japanese. The overall nutritional status of the Indians from the low socio-economic group in terms of weights and heights is poorer and have multiple nutrient deficiencies because of the cereal-based diets. The Chinese have an advantage of adequate weights, high soya intakes, higher intakes of $n-3$ fatty acids and shorter femoral neck lengths ${ }^{(25)}$. The femoral neck lengths have not been studied among the Indian population. The results of the present study throw light on the complex nature of this problem.

Overall lean body mass of the study group women was much lower and the fat percentage much higher than the Western women belonging to the same weight group ${ }^{(26)}$. When the lean body mass was analysed in relation to the occupation groups, it was observed that higher physical activities of sweepers and construction workers were not associated with a higher lean body mass when compared with the beedi makers. Lean body mass is known to be a major determinant of development and maintenance of BMD at the hip region $^{(27,28)}$. Muscle mass is the major constituent of lean body mass and the effect of physical activity on BMD is predominantly mediated by the muscle force. It may be speculated that in the absence of a broad range of nutrients required for muscle mass development ${ }^{(6,29)}$, physical activity did not help in muscle building in these women. In fact, the weight-bearing activities of construction workers in the absence of adequate nutrition were associated with a reduction in fat, for possibly energy expenditure, without increase in muscle mass (Table 2). The role of body composition and bone health in this group needs further investigation.

The present study thus highlights the problem of poor bone health of Indian low-income group women engaged in repetitive work. Load-bearing activities were not associated with better bone health probably due to the absence of adequate nutrition. It also raises important questions regarding the adequacy of cereal-based diets for women workers in whom osteoporosis sets in as early as 40 years of age.

\section{Acknowledgements}

The present study was funded by the Indian Council of Medical Research. The authors declare that they have no conflict of interest. V. S. and B. K. contributed to the study design, subject recruitment, interpretation of the results and manuscript preparation. K. U. carried out the dual-energy X-ray absorptiometry scans and analyses, G. C. R. and G. V. N. R. contributed to the recruitment of subjects and dietary $\mathrm{Ca}$ estimations. P. A. K. carried out biochemical estimations. N. B. carried out the statistical analysis of data.

The authors would like to thank the Directors of the National Institute of Nutrition, Hyderabad, India who provided the facilities and support system to carry out the present study. We are thankful to Mr A. N. Naidu (Retired Deputy Director), National Institute of Nutrition, Hyderabad, India for his valuable suggestions regarding statistical analyses. We are grateful to Ms Suvarna, Ms A. Padama Siromani, Mr R. Sambasiva Rao and Ms Malini V. Rao for their help during the course of the study. We thank Ms Sucheta Mehra who was associated during the early part of the study. The present study would not have been possible without the unstinting cooperation of the women from Addagutta, Hyderabad, India and we are grateful to them.

\section{References}

1. Gupta AK, Samuel KC, Kurian PM \& Raman RC (1967) Preliminary study of the incidence of aetiology of femoral neck fractures in Indians. Indian J Med Res 55, 1341-1348.

2. Vaishnava H \& Rizvi SNA (1974) Frequency of osteomalacia and osteoporosis in fractures of proximal femur. Lancet $\mathbf{i}$, 676-677.

3. Shatrugna V (1998) Osteoporosis in the Asian region: newer questions. In Diet, Nutrition and Chronic Diseases, pp. 81-83 [P Shetty and C Gopalan, editors]. London: Smith-Gordon.

4. Shatrugna V, Kulkarni B, Kumar PA, Usha Rani K \& Balakrishna N (2005) Bone status of Indian women from a low income group and its relationship to the nutritional status. Osteoporos Int 16, 1827-1835.

5. National Nutrition Monitoring Bureau (2002) Diet and Nutritional Status of Rural Population. Hyderabad, India: National Institute of Nutrition.

6. Shatrugna V, Balakrishna N \& Krishnaswamy K (2006) Effect of micronutrient supplement on health and nutritional status of school children: bone health and body composition. Nutrition 22, S33-S39.

7. Neville CE, Murray LJ, Boreham CAG, Gallagher AM, Twisk J, Robson PJ, Savage JM, Kemper HCG, Ralston SH \& Davey Smith G (2002) Relationship between physical activity and bone mineral status in young adults: The Northern Ireland Young Hearts project. Bone 30, 792-798.

8. Gustavsson A, Thorsen K \& Nordstrom P (2003) A 3 year longitudinal study of the effect of physical activity on the accrual of bone mineral density in healthy adolescent males. Calcif Tissue Int 73, 108-114.

9. Pongchaiyakul C, Nguyen TV, Kosulwat V, Rojroongwasinkul N, Charoenkiatkul S, Eisman JA \& Rajatanavin R (2004) Effects of physical activity and dietary calcium intake on bone mineral density and osteoporosis risk in a rural Thai population. Osteoporosis Int 15, 807-813.

10. Engelke K, Kemmler W, Lauber D, Beeskow C, Pintag R \& Kalender WA (2006) Exercise maintains bone density at spine and hip EFOPS: a 3 year longitudinal study in early postmenopausal women. Osteoporo Int 17, 133-142.

11. Murphy NM \& Carroll P (2003) The effect of physical activity and its interaction with nutrition on bone health. Proc Nutr Soc 62, 829-833

12. Coupland CAC, Grainge MS, Cliffe SJ, Hosking D \& Chilvers CED (2000) Occupational activity and bone mineral density in post menopausal women in England. Osteoporos Int 11, $310-315$ 
13. Sujatha T, Shatrugna V, Venkatramana Y \& Begum N (2000) Energy expenditure on household, childcare and occupational activities of women from urban poor households. Br J Nutr 83, 497-503.

14. Gustafsson JE (1976) Improved specificity of serum albumin determination and estimation of "acute phase reactants" by use of the broncresol green reaction. Clin Chem 22, 616-622.

15. Schiele F, Arthur Y, Floc'h AY \& Siest G (1988) Total, tartrate resistant and tartrate-inhibited acid phosphatases in serum biological variations and reference limits. Clin Chem 34, 685-690.

16. Cadeau BJ \& Malkin A (1973) A relative heat stability test for the identification of serum alkaline phosphatase isoenzymes. Clin Chim Acta 45, 235-242.

17. National Institute of Nutrition (2002, 2006) Annual Report. Hyderabad, India: National Institute of Nutrition.

18. Coupland CAC, Cliffe SJ, Bassey CJ, Grainge MJ, Hosking DJ \& Chilvers CE (1999) Habitual physical activity and bone mineral density in postmenopausal women in England. Int $J$ Epidemiol 28, 241-246.

19. Rideout CA, McKay HA \& Barr SI (2006) Self-reported lifetime physical activity and areal bone mineral density in healthy postmenopausal women: the importance of teenage activity. Calcif Tissue Int 79, 214-222.

20. Going S, Lohman T, Houtkooper L, et al. (2003) Effects of exercise on bone mineral density in calcium replete post menopausal women with and without hormone replacement therapy. Osteoporos Int 14, 637-643.

21. Cussler EC, Going SB, Houtkooper LB, Stanford VA, Blew RM, Flint-Wagner HG, Metcalfe LL, Choi JE \& Lohman TG (2005) Exercise frequency and calcium intake predict 4-year bone changes in postmenopausal women. Osteoporos Int 16, $2129-2141$

22. Jaglal SB, Kreiger N \& Darlington GA (1995) Life time occupational physical activity and risk of hip fracture in women. Ann Epidemiol 5, 321-324.

23. Hetland ML, Haarbo J \& Christiansen C (1993) Low bone mass and high bone turnover in male long distance runners. $J$ Clin Endocrinol Metab 77, 770-775.

24. Anderson JJB (1999) Plant based diets and bone health: nutritional implications. Am J Clin Nutr 70, Suppl. 3, 539S-542S.

25. Yan L, Crabtree NJ, Reeve JM, Zhou B, Dequeker J, Nijs J, Falch JA \& Prentice A (2004) Does hip strength analysis explain the lower incidence of hip fracture in the People's Republic of China? Bone 34, 584-588.

26. Jackson AS, Stanforth PR, Gagnon J, Rankinen T, Leon AS, Rao DC, Skinner JS, Bouchard C \& Wilmore JH (2002) The effect of sex, age and race on estimating percentage body fat from body mass index: The Heritage Family Study. Int $J$ Obes Relat Metab Disord 26, 789-796.

27. Vicente-Rodriguez G, Ara I, Perez-Gomez J, Dorado C \& Calber JA (2005) Muscular development and physical activity as major determinants of femoral bone mass acquisition during growth. Br J Sports Med 39, 611-616.

28. Liu-Ambrose T, Kravetsky L, Bailey D, Sherat L, Mundt C, Baxter-Jones A, Khan KM \& McKay HA (2006) Change in lean body mass is a major determinant of change in areal bone mineral density of the proximal femur: a 12-year observational study. Calcif Tissue Int 79, 145-151.

29. Phillips SM, Hanman JW \& Wilkinson SB (2005) Dietary protein to support anabolism with resistance exercise in young men. $J$ Am Coll Nutr 24, 134S-139S. 